\title{
Sociodemographic and health care factors in determining immunization defaulters among preschool children in Petaling District, Selangor: a cross-sectional study in Malaysia
}

\author{
Damyanthy Krishna, Nor Afiah Mohd Zulkefli* id, Salmiah Md Said and Aidalina Mahmud
}

\begin{abstract}
Background: Immunization is an effective public health intervention to reduce morbidity and mortality among children and it will become more effective if the child can receive the full course of recommended immunization doses. The objective of this study was to determine the prevalence of childhood immunization defaulters and its associated factors among children below 5 years attending registered child care centers in Petaling District, Selangor.

Methods: This was a cross-sectional survey among mothers with children below 5 years from 60 registered child care centers in District of Petaling, Selangor. Data was collected by a self-administered questionnaire from a total of 1015 mothers. Simple Logistic Regression, Chi-square or Fisher's exact test were performed to determine the association between individual categorical variables and childhood immunization defaulters. Multivariate logistic regression was used to determine the predictors of childhood immunization defaulters.

Results: The study showed that the prevalence rate for defaulting immunization was 20.7\%. After adjusting all confounders, six statistically significant predictors of childhood immunization defaulters were determined. They were non-Muslims ( $\mathrm{aOR}=1.669,95 \% \mathrm{Cl}=1.173,2.377, p=0.004)$, mothers with diploma and below educational background $(\mathrm{aOR}=2.296,95 \% \mathrm{Cl}=1.460,3.610, p<0.0001)$, multiple children of 5 and above in a family $(\mathrm{aOR}=2.656,95 \% \mathrm{Cl}=1.004,7.029, p=0.040)$, mothers with younger children aged 2 years and below (aOR= $1.700,95 \% \mathrm{Cl}=1.163,2.486, p=0.006)$, long travelling time of more than $30 \mathrm{~min}$ to the immunization health facility $(\mathrm{aOR}=2.303,95 \% \mathrm{Cl}=1.474,3.599, p<0.0001)$ and had delayed at least one of the immunization schedule $(\mathrm{aOR}=2.747,95 \% \mathrm{Cl}=1.918,3.933, p<0.0001)$.

Conclusion: This study highlights the need of implementation of intervention programs should be intensified to improve the childhood immunization status, focusing on the Non-Muslim community, mothers with low educational level, mothers with multiple children and mothers with children aged 2 years and below. In light of the growing problem of immunization defaulters in Malaysian children, identifying mothers at risk of not completing their children immunization schedule and educating them is an important strategy to recurrent outbreaks of infectious disease in the country.
\end{abstract}

Keywords: Immunization, Defaulters, Prevalence, Malaysia

\footnotetext{
* Correspondence: norafiah@upm.edu.my

Department of Community Health, Faculty of Medicine and Health Sciences,

University Putra Malaysia, 43400 Serdang, Selangor, Malaysia
}

(c) The Author(s). 2019 Open Access This article is distributed under the terms of the Creative Commons Attribution 4.0 International License (http://creativecommons.org/licenses/by/4.0/), which permits unrestricted use, distribution, and reproduction in any medium, provided you give appropriate credit to the original author(s) and the source, provide a link to the Creative Commons license, and indicate if changes were made. The Creative Commons Public Domain Dedication waiver (http://creativecommons.org/publicdomain/zero/1.0/) applies to the data made available in this article, unless otherwise stated. 


\section{Background}

According to the World Health Organization (2013), immunization is a process whereby a person is made immune or resistant to an infectious disease, typically with the administration of a vaccine (Immunization is a strategy of WHO to reduce the mortality rate of under-five year old children against eight vaccine-preventable diseases; tuberculosis, diphtheria, whooping cough (pertussis), tetanus, hepatitis B, polio, measles and respiratory diseases caused by Haemophilus influenza. Thus, to ensure immunization coverage sustains throughout the world, WHO launched the Expanded Program on Immunization (EPI) in 1974 and has significantly reduced the incidence of vaccine preventable diseases while preventing more than 2 million child deaths each year [1]. Thus, worldwide studies show that the cost to treat a vaccine preventable disease is 30 times more than the cost of the vaccine itself [2].

Despite this, the implementation of immunization programs varies greatly across different communities and there are at least 30 million children worldwide who are not routinely immunized [3]. In 2016, World Health Organization (WHO) reported that only $86 \%$ of children worldwide received three doses of diphtheria-tetanus-pertussis (DTP3) vaccine while an estimated 19.4 million children missed out these basic vaccines [1]. On the other hand, vaccine preventable diseases namely measles, whooping cough (pertussis) Haemophilus influenza type B (Hib) and tetanus remain a major disease burden among children in developing countries. The World Health Organization (WHO) and the United Nations Children's Funds (UNICEF) estimate that at least 1.5 million children under 5 years of age continue to die each year from vaccine-preventable diseases due to inadequate immunization coverage such as defaulted immunization, delayed immunization, incomplete or nonimmunization, mainly in Sub-Sahara Africa (SSA) and South-East Asia [3].

Malaysia being one of the developing nations in Southeast Asia, has also adopted the WHO's Expanded Programme of Immunization (EPI) in so as to reduce the burden from vaccine preventable diseases. The national immunization program based on the Ministry of Health's immunization schedule, stipulates that children should receive eight basic primary immunization and be completely immunized with the following vaccines by 12 months of age: one dose of Bacillus CalmetteeGuerin (BCG) and hepatitis B (HepB) vaccines at birth (or within $24 \mathrm{~h}$ of birth); two more doses of HepB vaccine at 1 and 6 months of age; three doses of diphtheria, tetanus and pertussis with Haemophilus influenzae type $\mathrm{b}(\mathrm{Hib})$ and inactivated poliovirus (IPV) (DTaPHib//IPV) at 2, 3 and 5 months of age; and one dose of mumps, measles, and rubella (MMR) vaccine at 12 months of age [4].

In the past decade, Malaysia has achieved high immunization coverage of more than $90 \%$ reported among children [4]. Despite its overwhelming success, childhood immunization is becoming a growing concern and huge challenges still persist in the country where outbreaks of vaccine-preventable diseases such as diphtheria and measles still occur sporadically $[4,5]$. Nonetheless, an increasing trend in vaccine hesitancy is being tracked by the Health Ministry of Malaysia (MOH) whereby a considerable number of parents with young children are refusing and defaulting immunization schedule, from 470 cases in 2013 to 1292 cases in 2014, based on data collected from government clinics and hospitals [6]. This underlines the particular need for continued monitoring of immunization program performance to detect potential problems and identify appropriate solutions.

Adapting from previous studies, factors associated with childhood immunization defaulters are maternal sociodemographic characteristics including maternal age, ethnicity, religion, marital status, educational level, working status, family composition and number of children, while child factors consist of child's age, gender and birth order $[7,8]$. Some factors related to the healthcare services that have been correlated with immunization include place of immunization, distance to immunization health facility, travelling time, waiting time to receive immunization and delayed immunization schedule may determine the health seeking behaviors of mother to default or immunize their children $[9,10]$. However, these factors may vary across and within cultures, and differs from one geographic and social setting to another [10].

A Malaysian study in Sabah conducted in government maternal child health clinics reported a defaulter rate of $16.8 \%$. The study noted that working mothers with bigger family size were significant factors associated with defaulters [11]. However, there was no study in Malaysia that investigated the relationship between immunization defaulters and the socio-demographic and healthcare factors among young children attending child care centers. Thus, this study aims to determine the prevalence and the predictors of childhood immunization defaulters among children below 5 years attending child care centers in Petaling District, Selangor. The findings from this study will add new knowledge in the respective field and will provide useful information for the government or policy makers in terms of planning an intervention or a campaign targeting mothers who are at risk of defaulting immunization by focusing on the significant predictors of this study.

\section{Materials and methods}

\section{Study location, study design, and study duration}

This study was a cross sectional study conducted among mothers of children aged 5 years and below attending child care centers in Petaling District, Selangor, Malaysia. Malaysia comprises of 13 large states and 3 different 
federal territories. Its area is about $330,803 \mathrm{~km}^{2}$. The Malaysian land is divided into two parts, namely Malaysian Borneo and Peninsular Malaysia, between which the South China Sea flows. The population of Malaysia was estimated in 2018 to be around 32.04 million [12]. Petaling is one of the districts located in the state of Selangor in Peninsular Malaysia. Petaling District covers an area of $484.32 \mathrm{~km}^{2}$ and has an estimated population of 1,782,375 in 2016 [13]. It has the highest population density and has been recognized as one of the most developed districts in Malaysia. This study was carried out over a period of 5 months, from July to November 2016.

Preschool education provided in child care centers known as Taska in Malaysia, caters to the education needs of children aged below 5 years [14]. The list of all child care centers registered under the Department of Social Welfare Malaysia located in Petaling District was used as a sampling frame. Particularly, there are 160 registered child care centers in Petaling District [15]. Child care centers were selected because they can yield the latest immunization data of young children below 5 years and capture the population of mothers utilizing the immunization services from both private and government health facilities. The age-range of 5 years and below was selected because most recommended immunizations would have been received by then. The study population was mothers with children aged 5 years and below who are attending the registered child care centers in Petaling District. Mothers were asked to serve as respondents in order to standardize data collection and because mothers are the primary caregivers of these children, thus they play an important role in the children's health and well-being [2].

\section{Sample size}

The sample size was estimated by using a two-proportion formula for hypothesis testing. It was determined using the Lemeshow, Hosmer, Klar, and Lwanga, (1990) formula with requirement for significance level $(\alpha)$ of 0.05 and $90 \%$ power, with the assumption of 5\% margin of error, 95\% confidence level [16]. A total of 996 respondents were required after adjustment for comparison of two groups, design effect of 2, estimated 10\% non-response rate and 10\% ineligibility.

\section{Sampling method}

Cluster sampling technique was employed for the selection of child care centers in Petaling District. Each selected child care centers were considered as cluster and was randomly selected using the two-digit table of random numbers. A total of 60 child care centers were approached to participate in this study and the principals gave permission to conduct this study in their institutions. All the mothers of children aged five and below from the selected child care centers were invited to participate in this study. Informed consent was obtained for participation in the study. Inclusion criteria were mothers with children aged 5 years and below attending registered child care centers during the study period. While, those mothers who refused to participate were mothers that were non-Malaysian citizens and children without their immunization record were excluded from this study.

\section{Definition of study variables}

The dependent variable in this study was immunization defaulters. Defaulters were defined as children who had defaulted on one or more doses of immunization from birth to their respective age group while those children who received all doses of immunization for their age were defined as immunization non-defaulters [2].

The independent variables were socio-demographic characteristics (maternal age, religion, ethnicity, educational status, marital status, working status, number of children), child factors (age, gender and birth order) and healthcare factors (place of immunization, distance to the preferred immunization facility, travelling time, waiting time to obtain immunization and delayed immunization schedule). These variables were chosen based upon prior studies illustrating their association with immunization defaulters.

\section{Study instruments and data collections}

For the purpose of data collection, a 17 -item pre-tested questionnaire was developed as the instrument for this study (Additional file 1). The questionnaire consisted of three sections that covered maternal, child, immunization history and health service related factors. The questionnaire was adapted and modified from the Expanded Program of Immunization (EPI) surveys [17] and existing literature $[11,18]$. The immunization status of the children was assessed as per the recommended national immunization schedule used during the time of study. Mothers were asked to use their child's immunization records to indicate the recommended vaccines and doses their children had received, focusing on the eight-basic primary immunization recommended by the Ministry of Health Malaysia; BCG, Hepatitis Dose 1, 2 and 3, Diphtheria-Tetanus-Pertussis-Haemophilus Influenza (Hib) Dose 1, 2 and 3, and Measles-Mumps-Rubella. The information given by the respondents were then further counterchecked with the Ministry of Health Malaysia Child's Health Booklet to reduce the likelihood of inaccurate reporting and avoid recall bias.

A pilot study was carried out among 100 mothers of children below 5 years who were randomly selected from four registered child care centers in Gombak District which was not selected in the main study. The questionnaires were 
pre-tested for face validity, content validity and internal consistency. The content validity was done by professionals from the Faculty of Medicine and Health Sciences, University Putra Malaysia. The professionals were three experts, who are specialists in family medicine, community health and family health fields. The results of the reliability test of the questionnaire showed that the internal consistency was acceptable with Cronbach's alpha ranged from 0.712 to 0.891. The questionnaire was bilingual, in English and Bahasa Malaysia language (national language of Malaysia). The questionnaire was translated from English to Malay by a professional language translator. The Malay version was used for the better understanding of the respondents.

\section{Data analysis}

The data collected were analyzed using the International Business Machine Statistical Package for Social Sciences (IBM SPSS) version 22 (SPSS Inc., Chicago, IL, USA). Data were entered, checked for data entry errors, explored and cleaned. The normality of the data was checked using the KolmogorovSmirnov test of normality. Descriptive analysis such as frequency, percentage, median, and interquartile range, were used to summarize and explain characteristics of the independent and dependent variables. Chi-square or Fisher's exact test was conducted to determine the association between the variables.

All tests of significance were based on $p<0.05$ level and confidence interval of $95 \%$ was applied. Variables with a $p$-value of less than 0.25 from the bivariate analysis were subjected to binary logistic regression. Multivariate binary logistic regression was used to determine the predictors of immunization defaulters. Fifteen variables were analyzed using backward and forward likelihood ratio (LR) stepwise selection methods. Both the forward LR and backward LR selected 6 similar significant variables. The 6 significant variables were then analyzed using the 'Enter' method to obtain the final model. There was no multicollinearity; and there was no significant interaction between the variables. The final model includes the predictors that influence the immunization defaulters. Adjusted odds ratios (aOR) with 95\% confidence intervals $(\mathrm{CI})$ were calculated. $P$ values less than 0.05 were considered statistically significant [19].

\section{Results}

\section{Response rate}

Out of 1514 respondents who were selected, 1015 participated and completed the questionnaire in this study, giving an overall response rate of $67 \%$. The remaining (33\%) 499 mothers were excluded because the questionnaires returned were incompletely answered (Fig. 1).

\section{Characteristics of respondents}

Table 1 shows the distribution of the respondents by socio-demographic characteristics of mothers and child. Majority of the mothers were between the ages of 30 to 39 years $(83 \%)$ with median age of 34 years. Most of the respondents were Malay (68.3\%) and Muslim (69.7\%). A large proportion of the respondents were married, constituting $98.4 \%$ of the total respondents whereas the remaining $1.6 \%$ was single, divorced or widowed. More than half of the respondents (89.4) had attained tertiary level education of bachelor's degree and above. In this study, majority of the mothers, $88.9 \%$, were working while the rest, $11.1 \%$, were not working. For family composition, $88.1 \%$ of respondents belonged to a family of 5 and below members. Most respondents (36.9\%) reported had 2 children. For child factors, a large proportion of the children (79.5) were 2 years or above. The median age for the children was 40 months (IQR: 23). Besides that, nearly half of the children, 494 (48.7\%) were male. The highest percentage of the participating children (36.9\%) was in the birth order of second.

The distribution of respondents according to place of immunization indicated that more than half of the respondents, $63 \%$, immunize their children mainly in government clinic. As for the distance to the preferred immunization health facility, $57.1 \%$ of the participating mothers reported a distance of 1 to $5 \mathrm{~km}$ (57.1\%) with a median distance of $5 \mathrm{~km}$ (IQR $7 \mathrm{~km}$ ). Nearly half of the total respondents travelled less than $15 \mathrm{~min}$ to the regularly visited immunization health facility (45.4\%). The median travelling time was 15 min (IQR 10). Particularly, $34.1 \%$ of the mothers reported that they waited less than $60 \mathrm{~min}$ with a median time of $60 \mathrm{~min}$ (IQR 90). Amongst all the 1015 children, $20.7 \%$ of them have delayed their immunization schedule by over 30 days for at least one dose of immunization and the rest had received all the recommended immunizations within 1 month of due date $(79.3 \%)$.

\section{Prevalence of childhood immunization}

The prevalence of childhood immunization among children aged 5 years and below attending child care centers in Petaling District was $20.7 \%$ for defaulters and $79.3 \%$ for non-defaulters. From the 210 respondents in the defaulter group, DTaP/IPV/Hib booster dose was most frequently defaulted in 131 (62.4\%) children, followed by $\mathrm{DTaP} / \mathrm{IPV} / \mathrm{Hib}$ third dose in 124 (59\%) children. Among the doses of Hepatitis B immunization, the third dose had the most defaulters $(22.4 \%)$ followed by the second dose (10.5\%) while the least rate of defaulters was for the first dose (4.8\%). The rate of defaulters for MMR immunization was $24.3 \%$. In addition, 15 children had not received BCG immunization against tuberculosis (Table 2). 


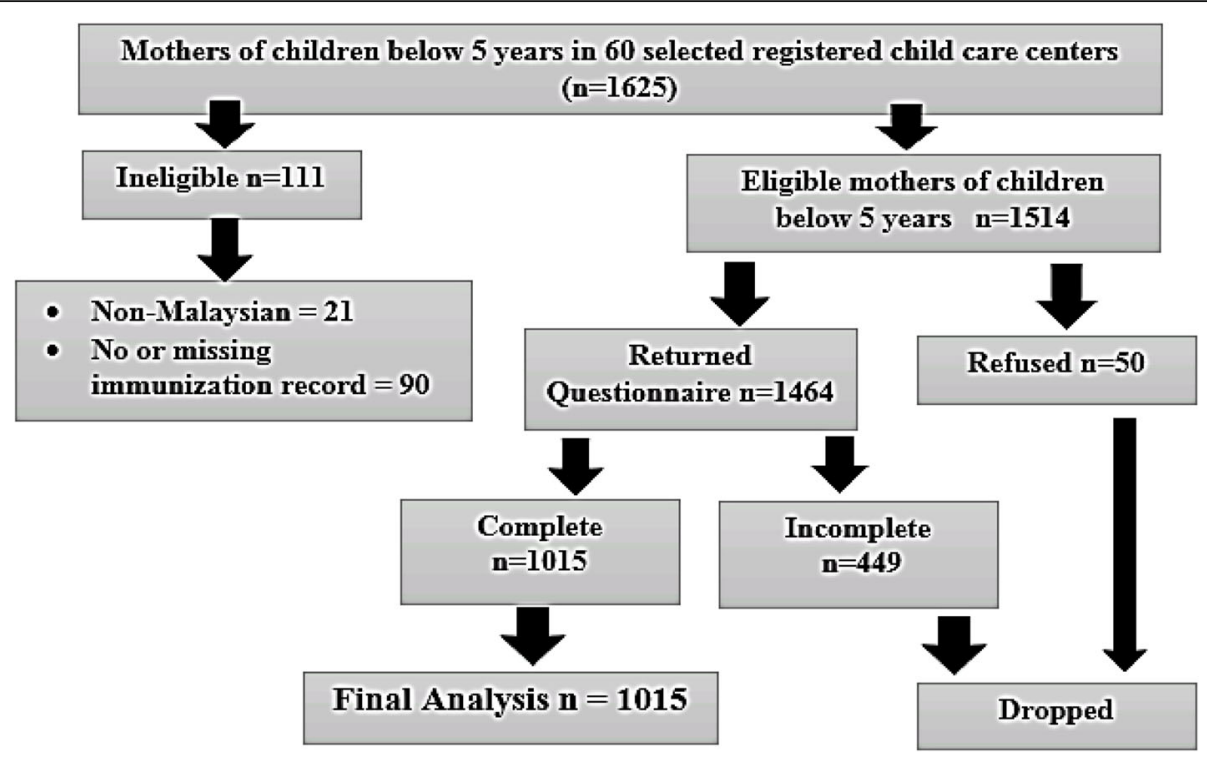

Fig. 1 Flow chart of the recruitment of the respondents

Table 3 shows the factors associated with immunization defaulters. The results show that there was a significant association between immunization defaulters and maternal age $\left(\chi^{2}=18.811, d f=2, p<0.0001\right)$, ethnicity $\left(\chi^{2}=22.325\right.$, $d f=1, p<0.0001)$ and religion $\left(x^{2}=14.096, d f=1, p<\right.$ $0.0001)$. According to age group, the mothers in the older group tend to have higher percentage of defaulters. Between ethnicity and religion, there were more defaulters among the Non-Malay and Non-Muslim group respectively. Among mothers living without partners such as those who were singled, divorced or widowed, $81.3 \%$ of them were found in the defaulter group, whereas only $18.8 \%$ of them were found in the non-defaulter group and this difference was statistically significant (Fisher Test $p<0.0001$ ).

Maternal highest educational level was also found to have a statistically significant association with immunization defaulters ( $x^{2}=38.386, d f=1, p<0.0001$ ). Specifically, $43.5 \%$ of mothers with diploma and below educational background had defaulted on their children's immunization compared to $18.0 \%$ of mothers who completed at least bachelor's degree or postgraduate studies. Mother's working status also showed a significant difference between the two groups in which $31.0 \%$ of mothers who were not working defaulted compared to $19.4 \%$ of working mothers defaulted $(\chi 2=8.195, d f=1, p=0.004)$. The difference between immunization defaulters of children belonging to a larger family size of more than 5 members and smaller family size with at least 5 members or less found to be significant $\quad\left(\chi^{2}=16.459, \quad d f=1, \quad p<0.0001\right) . \quad$ A significant association was found between the number of children within the family with immunization defaulters $\left(x^{2}=\right.$ $19.108, d f=2, p<0.0001)$. The more number of children within a family, the higher the percentage of immunization defaulters.

Besides, the result also shows that there was a significant association between childhood immunization defaulters and child's age $\left(\chi^{2}=6.195, \mathrm{df}=1, p=0.013\right)$, gender $\left(\chi^{2}=\right.$ 4.572, $d f=1, p=0.032)$ and birth order $\left(\chi^{2}=13.033, d f=\right.$ $1, p<0.0001)$. The result also shows that place of immunization $\left(x^{2}=6.356, d f=2, \quad p=0.042\right)$, distance $\left(\chi^{2}=11.866, d f=1, p=0.001\right)$, travelling time $\left(\chi^{2}=26.331\right.$, $d f=2, \quad p<0.0001)$ and delayed immunization schedule $\left(\chi^{2}=60.171, d f=1, p<0.0001\right)$ were found to have significant association with immunization defaulters. However, there was no significant association observed between the waiting time to get the child immunized and childhood immunization $(p>0.05)$.

In the binary regression logistic analysis, independent variables that were possibly associated with childhood immunization defaulters were entered into the logistic regression model. There was no multicollinearity; and there was no significant interaction between the variables. The variables that were retained in the final logistic regression model were religion, educational level, number of children, child's age group, travelling time to health facility and delayed immunization schedule.

Table 4 presents the results of binary logistic regression to determine the predictors of childhood immunization defaulters. The predictors of childhood immunization defaulters were non-Muslims (adjusted $\mathrm{OR}=1.669,95 \% \mathrm{CI}=1.173,2.377, p=0.004)$, mothers with diploma and below educational background (adjusted $\mathrm{OR}=2.296,95 \% \mathrm{CI}=1.460,3.610, \quad p<0.0001)$, multiple children of 5 and above in a family (adjusted 
Table 1 Distribution of respondents by socio-demographic characteristic, child factors and healthcare factors ( $N=1015)$

\begin{tabular}{|c|c|c|}
\hline & Frequency (n) & Percentage (\%) \\
\hline \multicolumn{3}{|l|}{ Socio-demographic characteristics } \\
\hline \multicolumn{3}{|l|}{ Mother's age (years) } \\
\hline 20 to 29 & 107 & 10.5 \\
\hline 30 to 39 & 842 & 83.0 \\
\hline 40 and above & 66 & 6.5 \\
\hline \multicolumn{3}{|l|}{ Ethnicity } \\
\hline Malay & 693 & 68.3 \\
\hline Chinese & 188 & 18.5 \\
\hline Indian & 119 & 11.7 \\
\hline Others $^{a}$ & 15 & 1.5 \\
\hline \multicolumn{3}{|l|}{ Religion } \\
\hline Muslim & 707 & 69.7 \\
\hline Buddhist & 160 & 15.8 \\
\hline Hindu & 100 & 9.9 \\
\hline Christian & 45 & 4.5 \\
\hline Others $^{b}$ & 3 & 0.3 \\
\hline \multicolumn{3}{|l|}{ Marital Status } \\
\hline Married & 999 & 98.4 \\
\hline Single/Divorced/Widowed & 16 & 1.6 \\
\hline \multicolumn{3}{|l|}{ Educational Level } \\
\hline Secondary school & 28 & 2.8 \\
\hline Pre-university & 13 & 1.3 \\
\hline Certificate or Diploma & 67 & 6.6 \\
\hline Bachelor's Degree & 696 & 68.6 \\
\hline Postgraduate studies & 211 & 20.8 \\
\hline \multicolumn{3}{|l|}{ Working Status } \\
\hline Working & 902 & 88.9 \\
\hline Not-working & 113 & 11.1 \\
\hline \multicolumn{3}{|l|}{ Family Composition } \\
\hline 5 and below & 894 & 88.1 \\
\hline Above 5 & 121 & 11.9 \\
\hline \multicolumn{3}{|l|}{ Number of Children } \\
\hline 1 & 359 & 35.4 \\
\hline 2 & 375 & 36.9 \\
\hline 3 and above & 281 & 27.7 \\
\hline \multicolumn{3}{|l|}{ Child Factors } \\
\hline \multicolumn{3}{|l|}{ Child's Age } \\
\hline 2 years and below & 208 & 20.5 \\
\hline Above 2 years & 807 & 79.5 \\
\hline \multicolumn{3}{|l|}{ Child's Gender } \\
\hline Male & 494 & 48.7 \\
\hline Female & 521 & 51.3 \\
\hline
\end{tabular}

Child's Birth Order
Table 1 Distribution of respondents by socio-demographic characteristic, child factors and healthcare factors $(N=1015)$ (Continued)

\begin{tabular}{|c|c|c|}
\hline & Frequency (n) & Percentage (\%) \\
\hline First & 359 & 35.4 \\
\hline Second & 375 & 36.9 \\
\hline Third and above & 281 & 27.7 \\
\hline \multicolumn{3}{|l|}{ Healthcare Factors } \\
\hline \multicolumn{3}{|l|}{ Place of Immunization } \\
\hline Government clinic & 639 & 63.0 \\
\hline Government hospital & 77 & 7.6 \\
\hline Private clinic & 330 & 32.5 \\
\hline Private hospital & 148 & 14.6 \\
\hline \multicolumn{3}{|c|}{ Distance to health facility (km) } \\
\hline 1 to 5 & 580 & 57.1 \\
\hline 6 to 10 & 253 & 24.9 \\
\hline More than 10 & 182 & 17.9 \\
\hline \multicolumn{3}{|l|}{ Travelling time (minutes) } \\
\hline Less than 15 & 461 & 45.4 \\
\hline 15 to 29 & 378 & 37.2 \\
\hline 30 and above & 176 & 17.3 \\
\hline \multicolumn{3}{|l|}{ Waiting time (minutes) } \\
\hline Less than 60 & 348 & 34.3 \\
\hline 60 to 119 & 329 & 32.4 \\
\hline 120 and above & 338 & 33.3 \\
\hline \multicolumn{3}{|c|}{ Delayed immunization schedule } \\
\hline Yes & 210 & 20.7 \\
\hline No & 805 & 79.3 \\
\hline
\end{tabular}

ather ethnicities were Orang Asli, Dusun, Rungus, Kadazan, Iban and Punjabi ${ }^{\mathrm{b}}$ Other religions were no religion, Sikh and Bahai

$\mathrm{OR}=2.656,95 \% \mathrm{CI}=1.004,7.029, p=0.040)$, mothers with younger children aged 2 years and below (adjusted $\mathrm{OR}=1.700,95 \% \mathrm{CI}=1.163,2.486, p=0.006$ ), long travelling time of more than $30 \mathrm{~min}$ to the immunization health facility (adjusted $\mathrm{OR}=2.303,95 \% \mathrm{CI}=1.474$, $3.599, p<0.0001)$ and delayed at least one of the immunization schedule (adjusted $\mathrm{OR}=2.747,95 \% \mathrm{CI}=$ $1.918,3.933, p<0.0001)$.

The significance levels of the Wald statistics demonstrated that all the 6 predictor variables made a significant contribution to immunization defaulters after adjusting other variables. The Hosmer-Lemeshow test showed a $p$-value of 0.421 which means that it is not statistically significant, implying that the logistic regression model was statistically significant and fits the sample $(\mathrm{x} 2=7.078, d f=7, p=0.421)$. This study found that those factors can explain $16.6 \%$ of the variation in the factors influencing immunization defaulters. 
Table 2 Distribution of defaulters according to types of immunization $(n=210)$

\begin{tabular}{llll}
\hline Type of Immunization & Recommended age given (months) & $\mathrm{n}$ & Percentage of defaulting \% \\
\hline BCG & Birth & 15 & 7.1 \\
Hepatitis B - 1st dose & Birth & 10 & 4.8 \\
Hepatitis B - 2nd dose & 1 & 22 & 10.5 \\
Hepatitis B - 3rd dose & 6 & 47 & 22.4 \\
DTaP/IPV/Hib 1st dose & 2 & 84 & 40.0 \\
DTaP/IPV/Hib 2nd dose & 3 & 100 & 47.6 \\
DTaP/IPV/Hib 3rd dose & 5 & 124 & 59.0 \\
MMR & 12 & 51 & 24.3 \\
DTaP/IPV/Hib booster dose & 18 & 131 & 62.4 \\
\hline
\end{tabular}

BCG Bacillus Calmette-Guérin, HepB Hepatitis B, DTaP Diphtheria, Tetanus, Acellular Pertussis, Hib Haemophilus influenzae b, IPV Inactivated Poliovirus, MMR Mumps, Measles, Rubella

\section{Discussion}

Based on previous Malaysian studies, prevalence of childhood immunization defaulters ranges from 16.8 to $24.8 \%[11,18]$. The results of this study identified that the prevalence of immunization defaulters among children below 5 years attending registered child care centers in Petaling District, Selangor was 20.7\%, falling within that range. This shows that $20.7 \%$ of the children in this study had default or missed at least one of the recommended immunization schedules, thus making them unprotected or inadequately protected against these vaccine-preventable diseases.

The proportion of children who had defaulted immunization varied for the different vaccines doses. The most commonly defaulted immunization in defaulters group is DTaP/IPV/Hib booster dose. This shows that the majority of the defaulted children were lack of booster dose to fully protect them against a vaccine preventable disease. The lack of awareness on the necessity to return for booster vaccine doses may influence mothers not to bring their children again for immunization. In this study, a consistent increase in immunization defaulters from the first to the third dose was observed in DTaP/IPV/Hib (40.0, 47.6, 59.0\%) and Hepatitis B $(4.8,10.5,22.4 \%)$ vaccine, respectively. This shows that a repeated dose of an immunization increased the rate of defaulting subsequent doses, similar to what has been reported by Azhar et al. among children in Sabah, Malaysia [11]. The possible explanation for such finding could be due to the result of time gap between two vaccine leading mothers to forget the subsequent dose [11].

Waiting time was not a significant factor for childhood immunization defaulters. The possible explanation for the insignificant result in this study could be due to the availability of the immunization health facilities approximately within five kilometers from their houses and free immunization provided by government hospitals or clinics to the children may have benefited the mothers and outweighed the risks of defaulting immunization. The result contradicts with the results found by Lim et al. [20] and Abdulraheem et al. [21] where the authors found a significant association between waiting time and incomplete immunizations. The differences in the findings could be due to the different study settings by Lim et al. [20] and Abdulraheem et al. [21] as both were conducted in government healthcare centers whereas this study was conducted in child care centers, whereby services were received from government, private or both facilities.

This study pointed out that religion $(p<0.0001)$ was found to be significantly associated with immunization defaulters. Similar findings were also observed by other researchers in Australia and India [22-24]. The immunization defaulters were significantly higher among non-Muslim respondents compared to respondents of Muslim religious belief from the majority ethnic group. This finding was similar and supported by a recent Malaysian study on vaccine hesitancy among parents in a tertiary hospital in Kuala Lumpur which found that nonMuslim parents were significantly more vaccine hesitant than Muslim parents $(p<0.026)$ [25]. The possible reason could be due to the vaccine safety concern that may influence the immunization decision among the nonMuslims primarily Chinese and Indian parents [26].

Further, the results found a significant association between maternal education levels with immunization defaulters in children. The importance of education level in influencing immunization status among children was also proven by studies from other developing countries [27-30]. This study shows that children borne from less educated mothers, with diploma and below, tend to default immunization schedule compared to children borne from more educated counterparts, with bachelor's degree and above. Mother's educational level could also influence the knowledge one has on childhood immunization which could eventually influence one's decision on their children's health [31]. Maternal education 
Table 3 Factors associated with immunization defaulters ( $N=1015)$

\begin{tabular}{|c|c|c|c|}
\hline Socio-demographic characteristics & Defaulter n (\%) & NonDefaulter n (\%) & $p$ value \\
\hline \multicolumn{4}{|l|}{ Mother's age (years) } \\
\hline 20 to 29 & $25(23.4)$ & $82(76.6)$ & \multirow[t]{3}{*}{$<0.0001^{*}$} \\
\hline 30 to 39 & $158(18.8)$ & $684(81.2)$ & \\
\hline 40 and above & $27(40.9)$ & $39(59.1)$ & \\
\hline \multicolumn{4}{|l|}{ Ethnicity } \\
\hline Malay & $115(16.6)$ & $578(83.4)$ & \multirow[t]{2}{*}{$<0.0001^{*}$} \\
\hline Non-Malay & $95(29.5)$ & $227(70.5)$ & \\
\hline \multicolumn{4}{|l|}{ Religion } \\
\hline Muslim & $124(17.5)$ & $583(82.5)$ & \multirow[t]{2}{*}{$<0.0001^{*}$} \\
\hline Non-Muslim & $86(27.9)$ & $222(72.1)$ & \\
\hline \multicolumn{4}{|l|}{ Marital status } \\
\hline Married & $197(19.7)$ & $802(80.3)$ & \multirow[t]{2}{*}{$<0.0001^{*+}$} \\
\hline Single/divorcee/widow & $13(81.3)$ & $3(18.8)$ & \\
\hline \multicolumn{4}{|l|}{ Educational level } \\
\hline Diploma and below & $47(43.5)$ & $61(56.5)$ & \multirow[t]{2}{*}{$<0.0001^{*}$} \\
\hline Degree and above & $163(18.0)$ & $744(82.0)$ & \\
\hline \multicolumn{4}{|l|}{ Working status } \\
\hline Working & $175(19.4)$ & $727(80.6)$ & \multirow[t]{2}{*}{$0.004^{*}$} \\
\hline Not-working & $35(31.0)$ & $78(69.9)$ & \\
\hline \multicolumn{4}{|l|}{ Family composition } \\
\hline 5 and below & $168(18.8)$ & $726(81.2)$ & \multirow[t]{2}{*}{$<0.0001^{*}$} \\
\hline Above 5 & $42(34.7)$ & $79(65.3)$ & \\
\hline \multicolumn{4}{|l|}{ Number of children } \\
\hline 1 to 2 & $129(17.6)$ & $605(82.4)$ & \multirow[t]{3}{*}{$<0.0001^{*}$} \\
\hline 3 to 4 & $72(27.6)$ & $189(72.4)$ & \\
\hline 5 or higher & $9(45.0)$ & $11(55.0)$ & \\
\hline \multicolumn{4}{|l|}{ Child's age } \\
\hline 2 years and below & $56(26.9)$ & $152(73.1)$ & \multirow[t]{2}{*}{$0.013^{*}$} \\
\hline Above 2 years & $154(19.1)$ & $653(80.9)$ & \\
\hline \multicolumn{4}{|l|}{ Child's gender } \\
\hline Male & $116(23.5)$ & $378(76.5)$ & \multirow[t]{2}{*}{$0.032^{*}$} \\
\hline Female & $94(18.0)$ & $427(82.0)$ & \\
\hline \multicolumn{4}{|l|}{ Child's birth order } \\
\hline First born & $52(14.5)$ & $307(85.5)$ & \multirow[t]{2}{*}{$<0.0001^{*}$} \\
\hline Non-first born & $158(24.1)$ & $498(75.9)$ & \\
\hline \multicolumn{4}{|l|}{ Place of immunization } \\
\hline Government & $102(17.9)$ & $468(82.1)$ & \multirow[t]{3}{*}{$0.042^{*}$} \\
\hline Private & $84(24.7)$ & $256(75.3)$ & \\
\hline Mixed & $24(22.9)$ & $81(77.1)$ & \\
\hline \multicolumn{4}{|l|}{ Distance to health facility (km) } \\
\hline 1 to 5 & $98(16.9)$ & $482(83.1)$ & $0.001^{*}$ \\
\hline More than 5 & $112(25.7)$ & $323(74.3)$ & \\
\hline Travelling time to health facility (mi & & & \\
\hline Less than 15 & $63(13.7)$ & $398(86.3)$ & $<0.0001^{*}$ \\
\hline
\end{tabular}


Table 3 Factors associated with immunization defaulters $(N=1015)$ (Continued)

\begin{tabular}{lll}
\hline Socio-demographic characteristics & Defaulter $n(\%)$ & NonDefaulter $n(\%)$ \\
\hline 15 to 29 & $96(25.4)$ & $282(74.6)$ \\
30 and above & $51(29.0)$ & $125(71.0)$ \\
Waiting time (minutes) & & \\
Less than 60 & $83(23.9)$ & $265(76.1)$ \\
$60-119$ & $63(19.1)$ & $266(80.9)$ \\
120 and above & $64(18.9)$ & $274(81.1)$ \\
Delayed immunization schedule & & \\
Yes & $84(40.0)$ & $126(60.0)$ \\
No & $126(15.7)$ & $679(84.3)$ \\
\hline
\end{tabular}

*Significant at $p$ value $<0.05$

influences child health-care-seeking behavior whereby education increases knowledge and enables better understanding on immunization among mothers with higher education level [30].

This study revealed that the number of children was significantly associated with immunization defaulters. It was found that odds of a child being a defaulter increases with the number of children in the household. Similar findings were obtained from other studies in Malaysia that shows

Table 4 Binary logistic regression analysis of predictors of immunization defaulters

\begin{tabular}{|c|c|c|c|}
\hline Factors & Adjusted OR & $95 \% \mathrm{Cl}$ & $p$ value \\
\hline \multicolumn{4}{|l|}{ Religion } \\
\hline Muslim & 1 & & \\
\hline Non-Muslim & 1.669 & $1.173-2.377$ & $0.004^{*}$ \\
\hline \multicolumn{4}{|l|}{ Educational Level } \\
\hline Diploma and below & 2.296 & $1.460-3.610$ & $0.011^{*}$ \\
\hline Bachelor's degree and above & 1 & & \\
\hline \multicolumn{4}{|l|}{ Number of Children } \\
\hline 1 to 2 & 1 & & \\
\hline 3 to 4 & 1.599 & $1.109-2.307$ & $0.012^{*}$ \\
\hline 5 or higher & 2.656 & $1.004-7.029$ & $0.040^{*}$ \\
\hline \multicolumn{4}{|l|}{ Child's Age } \\
\hline 2 years and below & 1.700 & $1.163-2.486$ & $0.006^{*}$ \\
\hline Above 2 years & 1 & & \\
\hline \multicolumn{4}{|c|}{ Travelling time to health facility (minutes) } \\
\hline Less than 15 & 1 & & \\
\hline $15-29$ & 1.811 & $1.247-2.628$ & $0.002^{*}$ \\
\hline 30 and above & 2.303 & $1.474-3.599$ & $<0.0001^{*}$ \\
\hline \multicolumn{4}{|l|}{ Delayed immunization schedule } \\
\hline Yes & 2.747 & $1.918-3.933$ & $<0.0001^{*}$ \\
\hline No & 1 & & \\
\hline
\end{tabular}

that multiple children were a contributing factor to incomplete immunization $[18,25]$. This could suggest that greater number of children in families placed heavier burden on mothers, hence reducing the quality of care received by the children [32]. Besides that, this study also revealed that there is a significant association between child's age and immunization defaulters. Younger children below 2 years were found to have an increased likelihood of being immunization defaulters. This study is in accordance with other studies that shows child's age as a significant factor for defaulting immunization $[18,33]$. The reason could be due to the recent huge amounts of conflicting vaccine-safety information and misinformation on the Internet that could negatively influence current mothers' decision to immunize their children [34].

The results of this study are consistent with other recent studies in developing countries from Ethiopia [35] and Cameroon [36] which have also suggested that traveling time to the immunization sites had significant association with the utilization of immunization services. In the multivariate results, immunization defaulters increased with increasing traveling time to the immunization health facility. This could be due to the fact that if a health facility is located within a convenient proximity, it is likely to motivate mothers to adhere to the immunization schedule [35]. The findings from this study also showed that there was a significant association between delayed immunization schedule and immunization defaulters. A similar study in Ethiopia showed that delaying child immunization schedule was a predictor of defaulting from completion of child immunization [37]. Children whose mothers delay immunization may be at an increased risk of not receiving all recommended vaccine doses and may leave their children more vulnerable to vaccine-preventable diseases [38, 39], suggesting that mothers delayed immunization because of concerns about vaccine safety and child illnesses [38]. Thus, it is important that a 
child receives a complete series of immunizations according to the schedule.

\section{Strengths and limitations}

There are some limitations in this study that warrant discussion. Firstly, its cross-sectional study design does not allow causality to be established. Secondly, data collection was confined to registered child care centers in one district of Malaysia. Therefore, the study population may not represent the whole country. However, the results from this study could be said to represent mothers at-risk in Malaysia. As immunization status was assessed using only the child's immunization record, mothers without their child's immunization records were not included in this study and could have led to information biasness. There is a possibility that this group might not have received immunization as scheduled and thus escaped the analysis for identification of immunization defaulters. However, studies show that mothers' responses are accurate and provide generally adequate information even if they are said to underreport immunization uptakes $[40,41]$.

\section{Recommendations}

The following recommendations are suggested; as this was a cross-sectional study with inherent study limitations, prospective studies should be carried out with the focus on modifiable and non-modifiable risk factors for immunization defaulters among young children to strengthen the findings of this study. A qualitative study should also be considered to explore in depth on mothers' perception, acceptance, barriers and values placed on childhood immunization. Based on the finding of the predictors of immunization defaulters in this study, it is recommended to develop short community based educational programs to educate mothers, especially those in the high-risk group such as Non-Muslims, lower educational levels, multiple children and with younger children. The program should also include the risk of delaying immunization schedule and the benefits of completing the administration of immunization for children. Moreover, the mothers in the high-risk group should be given special attention and encouragement to immunize their children. An effective vaccine reminder system could be implemented, in order to encourage appropriate administration of booster doses to educate mothers at risk of defaulting immunization.

\section{Conclusion}

This study shows that monitoring the immunization status among children is important and necessary, as $20.7 \%$ of them were defaulters. The modifiable predictors of immunization defaulters in this study were traveling time to health facility, delayed immunization schedule while religion, educational level, number of children and child's age were the non-modifiable predictors of immunization defaulters in this study.

Follow-up systems, counseling on childhood immunization, and effective intervention programs designed to improve childhood immunization uptake among mothers are also needed, especially among non-Muslims, mothers with educational level of diploma and below, mothers with more than 5 children and mothers with children aged 2 years and below. Identifying mothers at risk of not completing their children's immunization schedule and educating them is an important strategy to prevent outbreaks of infectious diseases in the country.

\section{Additional files}

Additional file 1: *Questionnaire, *English language version. (PDF 267 $\mathrm{kb})$

\section{Acknowledgements}

We would like to acknowledge the Research and Ethical Committee of Medical Sciences, University Putra Malaysia (UPM) for approving this study. We also gratefully acknowledge the cooperation of all participating principals, teachers and mothers of children involved in this study.

\section{Authors' contributions}

DK conducted literature search, planned the study, carried out data collection, performed data analysis and interpretation and drafted the manuscript. Authors NA, SM and AM reviewed literature search, design of the study, data analysis and data interpretation. NA revised the manuscript and gave critical feedback. All authors read and approved the final manuscript.

\section{Authors' information}

DK is a Masters in Community Health candidate at University Putra Malaysia. NA is an Assistant Professor of Department of Community Health in the Faculty of Medicine and Health Sciences at the University Putra Malaysia and has published work related to the use of health information in childhood immunization. Authors SM and AM are medical senior lecturers at the Department of Community Health.

\section{Funding}

Not applicable.

\section{Availability of data and materials}

The datasets used and/or analyzed during the current study are available from the corresponding author on reasonable request.

\section{Ethics approval and consent to participate}

Ethical approval for this study was obtained from the Ethics Committee for Research Involving Human Subjects, University Putra Malaysia (UPM/TNCPI/ RMC/JKEUPM/ 1.4.18.1/F1). Before the commencement of the study, verbal permission from the principals of each selected child care centers in Petaling District was obtained after informing the objectives of the study and their right to remain or opt out of the study if they feel uncomfortable.

Participants' consent form and questionnaires used in the survey were mailed to the principals to seek their permission over the phone. Since mothers were the respondents of the study, so only verbal consent was obtained from the principals with the approval by the ethics committee. Informed content via a written consent form was also obtained from the respondents prior to data collection. Confidentiality of the respondents' answers was guaranteed. 


\section{Consent for publication}

Not applicable.

\section{Competing interests}

The authors declare that they have no competing interests.

Received: 20 November 2018 Accepted: 28 August 2019

Published online: 18 September 2019

\section{References}

1. World Health Organization. Immunization coverage. 2018. http://www.who.int/ news-room/fact-sheets/detail/immunization-coverage. Accessed 12 Feb 2018.

2. WHO. Training for mid-level managers: the EPI coverage survey. Expanded Programme on Immunization of the Department of Immunization, Vaccines and Biologicals 2005. WHO/EPI/MLM/91.10.

3. WHO \& UNICEF. Global Immunization data. 2017. https://www.who.int/ immunization/monitoring_surveillance/global_immunization_data.pdf. Accessed on 20 May 2018.

4. Ministry of Health Malaysia, Health facts. 2018. https://www.dosm.gov.my/ v1/index.php?r=column/ctwoByCat\&parent_id=115\&menu_id=LOpheU43 NWJWRWVSZkIWdzQ4TIhUUT09. Accessed on 2 Apr 2018.

5. Abdullah AC, Nor Afiah MZ, Rosliza AM. Practice of childhood immunizations among parents and their associated factors in Hulu Langat, Selangor, Malaysia. Int J Public Health Clin Sci. 2016;3(6):94-104.

6. Loh FF. Necessary to vaccinate. The Star online. https://www.thestar.com. my/news/nation/2015/10/18/necessary-to-vaccinate-doctors-parents-whodont-immunise-kids-are-endangering-them/. Accessed on 4 May 2018.

7. Bugvi AS, Rahat R, Zakar R, Zakar MZ, Fischer F, Nasrullah M, Manawar R. Factors associated with non-utilization of child immunization in Pakistan: evidence from the demographic and health survey 2006-07. BMC Public Health. 2014;14(232):1-7.

8. Rainey JJ, Watkins M, Ryman TK, Sandhu PBA, Banerjee K. Reasons related to non-vaccination and under-vaccination of children in low and middle income countries: findings from a systematic review of the published literature, 1999-2009. Vaccine. 2011;29(46):8215-21.

9. Adhikary M, Haque R, Tanira S. Determinants of child immunization under expanded programme on immunization (EPI) in a rural setting of Bangladesh. J Dhaka Med Coll. 2015;22(2):201-6.

10. Glatman-Freedman A, Nichols KA. The effect of social determinants on immunization programs. Hum Vaccin Immunother. 2012;8(3):293-301.

11. Azhar SS, Nirmal K, Safian N, Rohaizat H, Noor AA, Rozita H. Factors influencing childhood immunization defaulters in Sabah, Malaysia. Int Med J Malays. 2012;11(1):17-22.

12. World population review. 2018. http://worldpopulationreview.com/ countries/malaysia-population/. Accessed on 2 Feb 2018.

13. Department of statistics, Malaysia population distribution and basic demographic characteristics. (2016).https://www.dosm.gov.my/v1/index.php?r=column\%2 Fctheme\&menu id=LOpheU43NWJwRWVSZkIWdzQ4TIhUUT09\&bul_id= MDMxdHZjWTK1SjFzTzNkRXYzcVZjdz09. Accessed on 7 Mar 2018.

14. Liew SP. Child care services in Malaysia. Exchange-exchange Press 2007, 8284. https://www.childcareexchange.com/library/5017501.pdf. Accessed on 22 May 2018.

15. Department of Social Welfare Malaysia. 2014. http://www.jkm.gov.my/jkm/index php? $=$ =portal/map\&map_type=01\&id=blB5RIVjdVRpSk9kTmVNYWFkWFJjdz09. Accessed 26 Mar 2018.

16. Lemeshow S, Hosmer DW, Klar J, Lwanga SK, World Health Organization. Adequacy of sample size in health studies. Chichester: Wiley; 1990. http:// apps.who.int/iris/handle/10665/41607

17. WHO. Immunization coverage cluster survey reference manual. 2014.http:// www.who.int/immunization_monitoring/routine/immunization_coverage/ en/index2.html. Accessed on 21 July 2018.

18. Sekar S, Gill PK. Factors predicting childhood immunization status in the east coast of Sabah: a behavioural-ecological perspective. Malays J Paediatr Child Health. 2015;18(2):30-40.

19. Kesintha A, Rampal L, Sherina M, Kalaiselvam T. Prevalence and predictors of poor sleep quality among secondary school students in Gombak District, Selangor. Med J Malays. 2018;73(1):31-40.

20. Lim WY, Amar-Singh HSS, Jeganathan N, Rahmat H, Mustafa NA, Mohd Yusof FS, N-Julia MS. Exploring immunisation refusal by parents in the Malaysian context. Cogent Med. 2016;3(1):1142410. https://doi.org/10.1 080/2331205x.2016.1142410.
21. Abdulraheem IS, Onajole AT, Jimoh AG, Oladipo AR. Reasons for incomplete vaccination and factors for missed opportunities among rural Nigerian children. J Public Health Epidemiol. 2011;3(4):194-203.

22. Pearce A, Marshall H, Bedford H, Lynch J. Barriers to childhood immunisation: findings from the longitudinal study of Australian children. Vaccine. 2015;33(29):3377-83. https://doi.org/10.1016/j.vaccine.2015.04.089.

23. Rathi A, Meena GS. Study of coverage and determinants of immunization in children aged 1 to 3 years in a rural population of Delhi. Vietnam J Public Health. 2013;1(1):41-56.

24. Kumar D, Aggarwal A, Gomber S. Immunization status of children admitted to a tertiary-care hospital of North India: reasons for partial immunization or non-immunization. J Health Popul Nutr. 2010;28(3):300-4.

25. Azizi FS, Kew Y, Moy FM. Vaccine hesitancy among parents in a multi-ethnic country, Malaysia. Vaccine. 2017;35(22):2955-61. https://doi.org/10.1016/j. vaccine.2017.04.010

26. Wong LP, Sam I. Factors influencing the uptake of $2009 \mathrm{H} 1 \mathrm{~N} 1$ influenza vaccine in a multiethnic Asian population. Vaccine. 2010;28(28):4499-505. https://doi.org/10.1016/j.vaccine.2010.04.043.

27. Adedokun ST, Uthman OA, Adekanmbi VT, Wiysonge CS. Incomplete childhood immunization in Nigeria: a multilevel analysis of individual and contextual factors. BMC Public Health. 2017;17(1). https://doi.org/10.1186/ s12889-017-4137-7.

28. Mohamud AN, Feleke A, Worku W, Kifle M, Sharma HR. Immunization coverage of 12-23 months old children and associated factors in Jigjiga District, Somali National Regional State, Ethiopia. BMC Public Health. 2014; 14:865. https://doi.org/10.1186/1471-2458-14-865.

29. Tesfaye F, Tamiso A, Birhan Y, Tadele T. Predictors of immunization defaulting among children age 12-23 months in Hawassa Zuria District of southern Ethiopia: community based unmatched case control study. Int J Public Health Sci. 2014;3(3):185-93.

30. Bbaale E. Factors influencing childhood immunization in Uganda. J Health Popul Nutr. 2013;31(1):118-29. https://doi.org/10.3329/jhpn.v31i1.14756.

31. Nankabirwa V, Tylleskär T, Tumwine JK, Sommerfelt H. Maternal education is associated with vaccination status of infants less than 6 months in eastern Uganda: a cohort study. BMC Pediatr. 2010;10(92):1-9.

32. Luman ET, McCauley MM, Shefer A, Chu SY. Maternal characteristics associated with vaccination of young children. Pediatrics. 2003;111(1): 1215-8.

33. Emmanuel OW, Samuel AA, Helen KL. Determinants of childhood vaccination completion at a peri-urban hospital in Kenya, December 2013January 2014: a case control study. Pan Afr Med J. 2015;20(277):1-10. https://doi.org/10.11604/pamj.2015.20.277.5664.

34. Betsch C, Renkewitz F, Betsch T, Ulshöfer C. The influence of vaccinecritical websites on perceiving vaccination risks. J Health Psychol. 2010; 15(3):446-55.

35. Legesse $\mathrm{E}$, Dechasa W. An assessment of child immunization coverage and its determinants in Sinana District, Southeast Ethiopia. BMC Pediatr. 2015; 15(31):1-14.

36. Russo G, Miglietta A, Pezzotti P, Biguioh RM, Mayaka GB, Sobze MS, Rezza G. Vaccine coverage and determinants of incomplete vaccination in children aged 12-23 months in Dschang, west region, Cameroon: a cross-sectional survey during a polio outbreak. BMC Public Health. 2015;15(630):1-11. https://doi.org/10.1186/s12889-015-2000-2.

37. Tadesse H, Deribew A, Woldie W. Predictors of defaulting from completion of child immunization in South Ethiopia, may 2008: a case control study. BMC Public Health. 2009;9:150. https://doi.org/10.1186/1471-2458-9-150.

38. Smith PJ, Humiston SG, Parnell T, Vannice KS, Salmon DA. The association between intentional delay of vaccine administration and timely childhood vaccination coverage. Public Health Rep. 2010;125(4):534-41.

39. Omer SB, Salmon DA, Orenstein WA, Dehart MP, Halsey N. Vaccine refusal, mandatory immunization, and the risks of vaccine-preventable diseases. $\mathrm{N}$ Engl J Med. 2009;360(19):1981-8.

40. Gareaballah ET, Loevinsohn BP. The accuracy of mother's reports about their children's vaccination status. Bull World Health Organ. 1989;67:669-74.

41. Langsten R, Hill K. The accuracy of mothers' reports of child vaccination: evidence from rural Egypt. Soc Sci Med. 1998;46:1205-12. https://doi.org/1 0.1016/S0277-9536(97)10049-1.

\section{Publisher's Note}

Springer Nature remains neutral with regard to jurisdictional claims in published maps and institutional affiliations. 